\title{
O IMPACTO DOS PROCESSOS CANCELADOS NA REDE NACIONAL DE CUIDADOS CONTINUADOS INTEGRADOS NA REGIÃO NORTE DE PORTUGAL (2014-2015)
}

\author{
THE IMPACT OF THE PROCESSES CANCELED ON THE NATIONAL \\ NETWORK OF INTEGRATED CONTINUOUS CARE IN NORTH REGION OF \\ PORTUGAL (2014-2015) \\ EL IMPACTO DE LOS PROCESOS CANCELADOS EN LA RED NACIONAL \\ DE ATENCIÓN CONTINUA INTEGRADA EN LA REGIÓN NORTE DE \\ PORTUGAL (2014-2015)
}

\author{
Maria José Rainho (mjrainho@utad.pt)* \\ Ana Branca de Carvalho (acarvalho@estgl.ipv.pt)** \\ João Paulo Barreira (jpsbarreira@arsnorte.min-saude.pt)***
}

\section{RESUMO}

Este estudo tem como objetivo principal analisar o impacto dos processos cancelados na Rede Nacional de Cuidados Continuados Integrados ( $\mathrm{RNCCl}$ ) na região Norte de Portugal. É um estudo de natureza descritiva e retrospetiva, realizado entre 01 de julho de 2014 e 30 de junho de 2015. Num total de 9753 referenciações com vaga atribuída na RNCCI, 1058 processos foram cancelados, representando $11 \%$ do total. A análise de variância (ANOVA ONE-WAY) demonstrou existirem diferenças estatisticamente significativas entre o tempo de identificação e cancelamento de vaga com o motivo de cancelamento e a tipologia das unidades da RNCCI. Foi ainda feita uma comparação com dados mais recentes (2019), que mostram um agravamento dos tempos de atribuição de vaga em todas as tipologias da RNCCI, assim como o número de casos cancelados. Podemos concluir que, cinco anos depois, se mantém a relevância de analisar a rede na perspetiva desta investigação.

Palavras Chave: sistema nacional de saúde, rede nacional de cuidados continuados integrados, referenciação, processos cancelados.

\section{ABSTRACT}

This study has as main objective to analyse the impact of the cancelled processes in the National Network of Integrated Continuous Care (RNCCI) in the Northern region of Portugal. It is a descriptive and retrospective study, carried out between July 1, 2014 and June 30, 2015. In a total of 9753 referrals with a vacancy allocated at $\mathrm{RNCCI}, 1058$ cases were cancelled, representing $11 \%$ of the total. The analysis of variance (ANOVA ONE-WAY) demonstrated that there are statistically significant differences between the time of identification and vacancy cancellation with the reason for cancellation and the typology of RNCCl units. A comparison was also made with more recent data (2019) showing an increase in the times for assigning vacancies in all types of RNCCl, as well as the 
number of cancelled cases. We can conclude that five years later the relevance of analysing the network in the perspective of this investigation remains.

Palavras-chave: national health care system, national network of integrated continuous care, referral process, cancelled records.

\section{RESUMEN}

Este estudio tiene como objetivo principal analizar el impacto de los procesos cancelados en la Red Nacional de Atención Continúa Integrada (RNCCl) en la región Norte de Portugal. Se trata de un estudio descriptivo y retrospectivo, realizado entre el 1 de julio de 2014 y el 30 de junio de 2015. En un total de 9753 derivaciones con vacante asignada en el RNCCI, se cancelaron 1058 casos, lo que representa el $11 \%$ del total. El análisis de varianza (ANOVA ONE-WAY) demostró que existen diferencias estadísticamente significativas entre el momento de identificación y cancelación de la vacante por motivo de cancelación y la tipología de unidades RNCCl. También se realizó una comparación con datos más recientes (2019) que muestran un aumento en los tiempos para la asignación de vacantes en todo tipo de RNCCI, así como el número de casos cancelados. Se concluye que cinco años después se mantiene la relevancia sigue siendo analizar la red desde esta perspectiva de investigación.

Palabras clave: sistema nacional de salud, red nacional de cuidados continuados en Portugal, proceso de referencia, procesos cancelados.

* Professora Auxiliar na Universidade de Trás-os-Montes e Alto Douro/Centro de Estudos Transdisciplinares Para o Desenvolvimento CETRAD.

** Professora Adjunta na Escola Superior de Tecnologia e Gestão de Lamego - Instituto Politécnico de Viseu/Centro de Investigação em Serviços Digitais - CISeD.

*** Coordenador da Unidade de Cuidados na Comunidade Lamego, ECL, ACeS Douro Sul.

Submitted:24 ${ }^{\text {th }}$ March 2020

Accepted: $6^{\text {th }}$ March 2021 


\section{INTRODUÇÃO}

Embora a compreensão da necessidade de cuidados continuados tivesse surgido em Portugal, na década de 90, só em 2006 com o Decreto-Lei n.o 101/2006 de 6 de junho é que viria a ser criado um modelo aplicado no território continental, designado por Rede Nacional de Cuidados Continuados Integrados (RNCCl). Este modelo de prestação de cuidados deveria ser apropriado às necessidades do cidadão e centralizado no/a utente, onde este possa aceder aos cuidados necessários, no tempo e locais certos e pelo prestador mais adequado (Unidade de Missão para os Cuidados Continuados Integrados [UMCCI], 2009a, 2009b).

Segundo a UMCCI, no seu Guia da RNCCI (UMCCI, 2009b), a prestação de cuidados de saúde e de apoio social às pessoas idosas, principalmente apresentando uma situação de dependência, precisavam de estar interligados, com recurso a equipas multidisciplinares, cuja formação dos profissionais seja a adequada e de excelência face às necessidades da população-alvo. Todos estes fatores constituem uma base sólida de qualquer sistema de saúde para que se torne ajustado e possa responder às necessidades de uma população que está a envelhecer. Assim, uma vez que já existiam serviços de saúde e sociais que procuravam independentemente responder à crescente necessidade de cuidados destes grupos da população, foi necessário desenvolver uma estratégia articulando um conjunto de serviços no âmbito da Saúde e da Segurança Social.

Constitui a população-alvo da $\mathrm{RNCCl}$, as pessoas em situação de dependência, independentemente da idade, tendo como objetivo fundamental a prestação de cuidados continuados de saúde e de apoio social, de natureza preventiva, reabilitativa ou paliativa, prestados através de unidades de internamento e de ambulatório e de equipas hospitalares e domiciliárias (UMCCI, 2009a, 2009b). Esta realidade tem tido um enorme impacto na organização do sistema de saúde português e nos recursos destinados aos/às utentes que carecem destes cuidados específicos.

Segundo os Relatórios de Monitorização da RNCCl (Administração Central do Sistema de Saúde [ACSS], 2015a, 2019), no ano de 2019 foram referenciados para as tipologias que agora integram a RNCCI 43.4941 utentes (41.657 em 2014), representando um acréscimo de 4,4\% em relação a 2014 e destes 13.721 (15.070 em 2014) na região norte. O número de utentes assistidos/as em 2019 foi de 50.473 (48.299 em 2014), verificando-se um acréscimo de 4,5\% em relação a 2014. A população da RNCCI em 2019 com idade superior a 65 anos representou $84,4 \%$ do total, ligeiramente acima dos $83,4 \%$ verificados em 2014 . A população com idade superior a 80 anos representou 51,1\% do total em 2019 (45,1\% em 2014). Os principais motivos de referenciação em 2019 foram a "dependência de atividades de vida diária" (90\%) (91\% em 2014) e "ensino utente/cuidador/a informal (89,5\%) (87\% em 2014). A mediana de dias, desde a referenciação com a respetiva validação de critérios até a identificação de vaga, na região Norte em 2019 foi de 9,7 dias (6,9 dias em 2014) em Unidades de Convalescença (UC), 27,1 dias (23 dias em 2014) em Unidades de Média Duração e Reabilitação (UMDR), 28,8 dias (12,2 dias em 2014) em Unidades de Longa Duração e Manutenção (ULDM), 14 dias (3,8 dias em 2014) em Equipas de Cuidados Continuados Integrados (ECCI) e 5,1 dias em 2014 em Unidades de Cuidados Paliativos (UCP). Como se pode observar, o tempo de referenciação

\footnotetext{
${ }^{1}$ Excluídos 46 utentes das tipologias pediátricas e 210 utentes das tipologias de Saúde Mental, atualmente incluídas na RNCCl. Este valor não inclui os/as utentes referenciados/as para a tipologia Unidade de Cuidados Paliativos, que se encontra em rede própria e não são abordados nos relatórios de monitorização da RNCCI desde 2017.
} 
até à identificação de vaga aumentou substancialmente em todas as tipologias. Dos/das utentes referenciados/as e já identificados/as com critérios de admissão, houve cancelamento de episódios, outros utentes recusaram, e ocorreram óbitos após a referenciação. Em 2019, o valor percentual nacional do somatório destes três motivos representou $24,9 \%$ de utentes com critérios para admissão a nível nacional (21\% em 2014).

Pode-se então concluir que o número de utentes referenciados/as ou assistidos/as na RNCCI é considerável e o número de processos cancelados, apenas da região Norte, sofreu um aumento de 7,9\% de 2014 (cerca de 3.165 casos) a 2019 (cerca de 3.416 casos), apresentando certamente constrangimentos na gestão da referenciação para a $\mathrm{RNCCl}$, quer a nível do volume total, quer a nível dos tempos totais de demora de todo o processo até à admissão da pessoa na RNCCl.

Nos últimos anos, a RNCCI tem vindo a ser estudada em diversas perspetivas e temáticas. Alguns dos estudos realizados centram-se na adequação relativamente às necessidades da população (Gonçalves, 2013), nas dificuldades apresentadas pelas equipas dos Cuidados de Saúde Primários (CSP) na referenciação (Fernandes, 2013), nas características na referenciação de utentes para UCP (Dias, 2012), sobre o efeito da referenciação na demora média dos internamentos nos hospitais (Ferreira, 2012), na demora média desde a referenciação hospitalar até à admissão numa unidade da RNCCI (Carvalho et al., 2016; Rainho et al., 2020) ou, ainda, na eficiência dos cuidados continuados integrados (Monteiro, 2012), não existindo nenhum estudo que aprofunde as implicações na $\mathrm{RNCCl}$ do cancelamento dos processos de referenciação após ter sido disponibilizada vaga.

Existem vários estudos que confirmam a necessidade de implementação de cuidados continuados em diversos países, sendo que em todos eles essa "Rede" apresenta características próprias e diferenciadas, definidas por políticas de saúde e necessidades encontradas também diferenciadas. Apontam-se a Noruega e Holanda (Gibson, 2006), bem como Alemanha, Reino Unido, Itália e Espanha (Herrera et al., 2006), onde se pode encontrar diferenças que mudam completamente a estrutura da prestação destes cuidados, nomeadamente o financiamento, o processo de referenciação, o tempo de internamento e mesmo o local de prestação de cuidados. No entanto, todos eles apontam na mesma direção, reforçando este estudo quanto à necessidade de prestação de cuidados de saúde com uma gestão eficiente.

Tendo em conta a problemática subjacente, a população envolvida e os factos apresentados, juntamente com a escassez de estudos, não é possível ficar alheio ao impacto dos processos cancelados na $\mathrm{RNCCl}$ na região Norte. Assim, a pertinência deste estudo centra-se, desde logo, na premissa de existirem poucos estudos realizados sobre os processos de referenciação para a $\mathrm{RNCCl}$, que foram cancelados após atribuição de vaga, que casuísticas apresentam, quais os tempos médios de demora na atribuição de vaga, em que tipologia ocorreram, que motivos são apresentados para o justificar e quais as implicações que isso pode causar. Sendo assim, é o que se propõe tratar neste estudo. 


\section{REVISÃO DE LITERATURA}

\subsection{Evolução do Sistema de Saúde para a criação da RNCCI}

A introdução dos cuidados continuados em Portugal e no Sistema Nacional de Saúde (SNS) é considerada como uma revolução, revestindo-se de uma importância fundamental e crucial na remodelação dos serviços, considerada até uma das maiores desde 1978 (Campos, 2008). Assim, pela primeira vez as pessoas que se encontravam internadas em ambiente hospitalar puderam ver suprimidas as suas necessidades individuais de saúde, consoante o grau de dependência nas suas atividades de vida diária.

Mas a identificação desta necessidade sobreveio somente durante a década de 90 , tendo como resultado o Despacho Conjunto n.o 407/98, 15 de maio, entre o Ministério da Saúde (MS) e o Ministério do Trabalho e da Solidariedade Social, pelo qual aprovaram as diretrizes da intervenção articulada entre eles, dirigidos às pessoas em situação de dependência, porém, segundo a Entidade Reguladora da Saúde (ERS, 2013), os tipos de resposta criados mostraram-se insuficientes e ineficazes.

Em 2001, no sistema de saúde português a oferta em cuidados continuados ainda era apenas uma intenção, não possibilitando que qualquer pessoa em situação de dependência pudesse esperar uma normal recuperação (Campos, 2001). Embora tivessem surgido várias tentativas legislativas de resposta, como o Despacho Conjunto n.o 407/98 de 18 de junho contendo as primeiras orientações regulamentares de intervenção do apoio social em articulação com os cuidados de saúde, mantinha-se a necessidade e o problema, pois considerava-se que a legislação não seguia de encontro às necessidades apresentadas pela população em causa (Simões, 2010).

Em 2002 surge um delineamento da primeira rede nacional de cuidados continuados com a Resolução do Conselho de Ministros n.o 59/2002, de 22 de março de 2002, a qual demonstra ser atingível o objetivo dos cuidados continuados integrados, assentes em novas configurações organizativas.

Em 2003, através do Decreto-Lei n.o 281/2003 de 8 de novembro foi criada a rede de cuidados continuados, sendo a mesma composta pelas instituições públicas, sociais e privadas desde que se encontrassem habilitadas à prestação de cuidados de saúde de acordo o descrito na legislação, permitindo interligar e complementar os cuidados hospitalares e de saúde primários. Assim, neste momento, principalmente as Instituições Particulares de Solidariedade Social são incentivadas a desenvolver a rede dos cuidados continuados.

Em maio de 2004, em resultado do Decreto-Lei acima aludido, as misericórdias tornaram-se as impulsionadoras primordiais na materialização dos cuidados continuados, conduzindo à elaboração de um protocolo de cooperação entre a União das Misericórdias Portuguesas e o MS. Desse protocolo resultaram as diferentes tipologias de serviços, nomeadamente as unidades de internamento, unidades de recuperação global e unidades móveis domiciliárias. Para o acompanhamento desse protocolo foi criada uma comissão de acompanhamento de monitorização, mas a mesma viria a ser suspensa em março de 2005 (Despacho n.o 16234/2005 26 de julho, 2005).

Em abril de 2005, através da Resolução de Conselho de Ministros n.o 84/2005, foi criada a Comissão para o Desenvolvimento dos Cuidados de Saúde às Pessoas Idosas e às Pessoas 
em Situação de Dependência, tendo como principal objetivo percecionar as necessidades existentes, conhecer a oferta atual nessa área, para poder formular um modelo operacional.

Só em 2006, com o Decreto-Lei n.o 101/2006, de 6 de junho, viria a surgir a RNCCI, baseada numa intervenção integrada e articulada entre os setores da saúde e da segurança social, que em última instância surge como resposta ao aumento da esperança média de vida providenciando resposta a um conjunto de carências expostas no sistema de saúde português (Observatório Português dos Sistemas de Saúde, 2006).

\subsection{Rede Nacional de Cuidados Continuados Integrados}

A criação da RNCCI, de acordo com o preâmbulo do Decreto-Lei n. 101/2006, de 6 de junho, procura dar resposta às carências de cuidados, decorrentes do aumento da prevalência de pessoas com doenças crónicas incapacitantes, do aumento de pessoas idosas com dependência funcional, de utentes com patologia crónica múltipla e de pessoas com doença incurável em estado avançado e em fase final de vida.

Segundo o Decreto-Lei n.o 101/2006, de 6 de junho e a Portaria no 174/2014 de 10 de Setembro, a RNCCI tem por missão prestar os cuidados adequados, de saúde e apoio social, a todas as pessoas que, independentemente da idade se encontrem em situação de dependência, tendo em atenção a necessidade de diminuir os internamentos desnecessários, redução do reinternamento hospitalar, redução do número de altas hospitalares tardias, aumento da capacidade da intervenção dos serviços de saúde, que se concretiza através dos seguintes objetivos (UMCCI, 2011, p.3858):

- $\quad$ "A melhoria das condições de vida e bem-estar das pessoas em situação de dependência, através da prestação de cuidados continuados de saúde e de apoio social;

- A manutenção das pessoas com perda de funcionalidade ou em risco de perder, no domicílio, sempre que possam ser garantidos os cuidados terapêuticos e o apoio social necessários à provisão e manutenção de conforto e qualidade de vida;

- O apoio, o acompanhamento e o internamento tecnicamente adequados à respetiva situação;

- A melhoria contínua da qualidade na prestação de cuidados continuados de saúde e de apoio social;

- O apoio aos familiares ou prestadores informais, na respetiva qualificação e na prestação dos cuidados;

- A articulação e coordenação em rede dos cuidados em diferentes serviços, setores e níveis de diferenciação;

- A prevenção de lacunas em serviços e equipamentos, pela progressiva cobertura nacional, das necessidades das pessoas em situação de dependência em matéria de cuidados continuados integrados."

A missão da RNCCI (UMCCI, 2011, p.8) vem assim dar resposta ao conjunto de pressupostos internacionais definidos para o desenvolvimento dos cuidados continuados integrados e que são:

- "Necessidade de diminuir internamentos desnecessários e o recurso às urgências por falta de acompanhamento continuado; 
- Redução do reinternamento hospitalar ou internamento de convalescença dos idosos;

- Redução do número de altas hospitalares tardias (acima da média de internamento definida);

- Aumento da capacidade da intervenção dos serviços de saúde e apoio social ao nível da reabilitação integral e promoção da autonomia;

- Disponibilização de melhores serviços para o apoio continuado às pessoas em situação de fragilidade ou com doença crónica;

- Disponibilização de melhores serviços de apoio à recuperação da funcionalidade e continuidade de cuidados pós-internamento hospitalar;

- Flexibilização da organização e do planeamento dos recursos numa base de sistema local de saúde, através da identificação, pormenorizada, das necessidades de cuidados da população, a nível regional;

- Maior eficiência das respostas de cuidados agudos hospitalares."

A prestação de cuidados de saúde e de apoio social em 2014-2015 era assegurada pela RNCCI através de quatro tipos de resposta em unidades de internamento e uma em regime de ambulatório. Constituíam unidades de internamento as UC, UMDR, ULDM e UCP e, em regime de ambulatório, a ECCI (UMCCI, 2011).

A RNCCI reforçou a sua capacidade de resposta a partir de 2016, para assistir áreas específicas de cuidados, caso dos Cuidados Pediátricos Integrados (CPI), com início em junho de 2016, e de Saúde Mental (SM), com início em junho de 2017. A partir de 2017, a RNCCI passou a não incluir os dados relativos às UCP, entretanto autonomizados em rede própria (ACSS, 2017a, 2017b).

O Decreto-Lei n.o 101/2006, de 6 de Junho, a UMCCI (2011) e a Portaria no 174/2014 de 10 de setembro definem a quem se destinam as Unidade da RNCCI, bem como em que situações. As UC são destinadas a utentes que se encontram em fase de recuperação de um processo agudo ou re-agudização de um processo crónico, com elevado potencial de reabilitação com previsibilidade de internamento até 30 dias consecutivos, em situação de dependência decorrente de internamento hospitalar, passível de melhoria. As UMDR visam responder a necessidades transitórias, promovendo a reabilitação e independência, em situação clínica decorrente de recuperação de um processo agudo ou re-agudização de processo crónico, cuja previsibilidade de dias de internamento se situe entre 30 a 90 dias. As ULDM têm por finalidade proporcionar cuidados que previnam e/ou retardem o agravamento da situação de dependência, otimizando o estado de saúde, num período de internamento em regra superior a 90 dias. Visam responder a utentes com processos crónicos que apresentem diferentes níveis de dependência e graus de complexidade e que não possam, ou não devam ser cuidados em domicílio. As UCP destinam-se a utentes com doenças complexas em estado avançado, com evidência de falha da terapêutica dirigida à doença de base ou em fase terminal e que requerem cuidados para orientação ou prestação de um plano terapêutico paliativo. A ECCI atende utentes que se encontrem em domicílio na sua área geográfica de influência. Para as ECCI considera-se critério de referenciação específico para admissão, a situação de dependência em que estejam reunidas condições para a prestação domiciliária dos cuidados continuados integrados de que necessitam o/a utente e a sua família.

Segundo o relatório de monitorização do desenvolvimento e da atividade da $\mathrm{RNCCl}$ de 2014 (ACSS, 2015a), a rede era constituída por 587 equipas referenciadoras, designadamente: as Equipas de Gestão de Altas (EGA) e as Equipas de Referenciação (ER), 99 Equipas Coordenadoras Locais (ECL) e 5 Equipas Coordenadoras Regionais (ECR). Atualmente, todos 
os Centros Hospitalares, Unidades Locais de Saúde e Hospitais têm EGA e todos os Agrupamentos de Centros de Saúde (ACES) têm ER e ECL (ACSS, 2019).

Desde janeiro de 2019, a nível nacional, existe uma coordenação conjunta (Comissão Nacional de Coordenação da Rede Nacional de Cuidados Continuados Integrados), com representantes do Ministério do Trabalho, Solidariedade e Segurança Social (MTSSS) e do MS (Instituto da Segurança Social [ISS], 2019). A EGA de âmbito hospitalar e a ER de âmbito dos CSP asseguram, principalmente: 1) a articulação com as equipas terapêuticas hospitalares de agudos para a programação de altas hospitalares, ou a articulação com as equipas terapêuticas das Unidades de Saúde Familiar (USF) ou Unidades de Cuidados de Saúde Personalizados (UCSP); 2) a articulação com as ECR e ECL da Rede.

A ECL articula com a coordenação a nível regional, assegura o acompanhamento e a avaliação da $\mathrm{RNCCl}$ a nível local, bem como a articulação e coordenação dos recursos e atividades, no seu âmbito de referência, competindo-Ihes, principalmente: 1) divulgar informação atualizada à população sobre a natureza, número e localização das unidades e equipas da $\mathrm{RNCCl}$; 2) apoiar e acompanhar o cumprimento dos contratos e a utilização dos recursos das unidades e equipas da Rede; 3 ) promover o estabelecimento de parcerias para a prestação de cuidados continuados no respetivo serviço comunitário de proximidade; 4) promover o processo de admissão ou readmissão nas unidades e equipas da $\mathrm{RNCCl}$; 5) alimentar o sistema de informação que suporta a gestão da RNCCl.

A ECR articula com a coordenação aos níveis nacional e local e assegura o planeamento, a gestão, o controlo e a avaliação da Rede, competindo-lhes, principalmente: 1) laborar proposta de planeamento das respostas necessárias e propor a nível central os planos de ação anuais para o desenvolvimento da RNCCl e a sua adequação periódica às necessidades; 2) orientar e consolidar os planos orçamentados de ação anuais e respetivos relatórios de execução e submetê-los à coordenação nacional; 3) promover formação específica e permanente dos diversos profissionais envolvidos na prestação dos cuidados continuados integrados; 4) promover a celebração de contratos para implementação e funcionamento das unidades e equipas que se propõem integrar a RNCCl.

\subsection{Gestão do Processo de ingresso na RNCCI}

O planeamento da alta de utentes internados/as em hospitais do SNS requer o envolvimento da equipa do respetivo serviço hospitalar, a qual sinaliza à EGA essa necessidade. A nível da comunidade (domicílio, hospital privado ou outro local de residência), a referenciação de utentes é efetuada pela ER onde o/a utente está inscrito/a. A referenciação de utentes é efetuada na plataforma da Rede Nacional de Cuidados Integrados GESTCARE CCI, através do preenchimento de determinadas avaliações. Todos os registos obedecem ao princípio do processo único, com uma ficha de identificação do/a utente, à qual é agregada a informação dos vários episódios de referenciação.

$\mathrm{O}$ circuito de referenciação da RNCCl assenta em níveis operacionais, correspondentes às EGA/ER, ECL e ECR. As primeiras materializam o processo de referenciação, a ECL valida essa mesma referenciação, quer ao nível da adequação da tipologia como à condição do/a utente e cumprimento dos critérios de referenciação, à ECR compete a pesquisa regional de vaga, bem como a coordenação regional de todo o processo de referenciação. Após a atribuição de vaga em Unidades da RNCCI é responsabilidade da ECL articular com a EGA e/ou ER e com a Unidade que vai receber o/a utente, de modo a que o processo seja o mais rápido possível e 
assegurando que todas as diligências são tomadas para que a continuidade dos cuidados seja um facto irrevogável. Para melhor se compreender o processo de referenciação e ingresso de um utente na RNCCl, veja-se a Figura 1.

Os pontos 1 a 5 representam a fase de referenciação, desde a elaboração do processo pela EGA/ER e até se encontrar a aguardar vaga na RNCCI. De salientar que o esquema representa um processo elaborado com critérios inequívocos para ingresso na $\mathrm{RNCCI}$, informação clínica e social correta e suficiente, tipologia adequada e documentação em conformidade, o tempo decorrido depende essencialmente da existência ou não de constrangimentos relacionados com o mencionado anteriormente, sendo que a ECL dispõe de $48 \mathrm{~h}$ para a avaliação. É possível cancelar o processo por falta de critérios ou documentação adequada, não chegando, portanto, a entrar na lista de espera para atribuição de vaga (ponto1 até ponto 4).

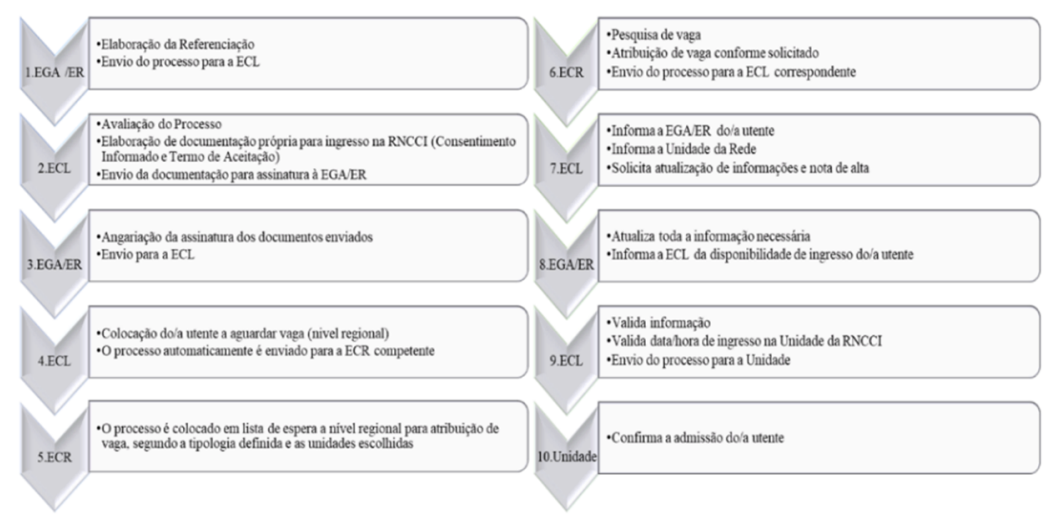

Figura 1 - Processo de ingresso na RNCCI

Os pontos 6 a 10 representam a fase de atribuição de vaga em unidades da RNCCl, desde a atribuição de vaga à confirmação da admissão do/a utente na unidade. Nesta fase torna-se necessário encetar todas as diligências para que o ingresso do/a utente na unidade que the foi atribuída seja o mais breve possível. Após o ponto 6, a vaga fica reservada para esse utente e não é possível ser ocupada por outro. O processo pode, no entanto, ser cancelado por recusa do/a utente, agravamento da situação clínica, alta clínica ou óbito.

O tempo total decorrido depende essencialmente da capacidade de articulação entre a ECL e a EGA/ER, e destas com as equipas terapêuticas hospitalares de agudos ou com as equipas terapêuticas das USF ou UCSP. O tempo decorrido entre os pontos 5 e 6 resulta da lista de espera para ingresso nas Unidades pretendidas, ou seja, o tempo de identificação de vaga. 0 tempo decorrido entre o ponto 7 e o ponto 10 resulta da articulação entre as Equipas da RNCCI e a condição do/a utente para ingresso, ou seja, o tempo de ingresso após colocação.

\subsection{Impacto Financeiro dos Cuidados Continuados}

A grande maioria das altas hospitalares em Portugal é de pessoas com mais de 65 anos de idade e, portanto mais vulneráveis à ocorrência de eventos adversos após a alta, com um crescimento de reinternamentos que pode estar associado a vários fatores entre os quais o 
envelhecimento per si, incumprimentos no regime e adesão terapêutica ou a cuidados de saúde inadequados no domicílio, requerendo uma continuidade dos cuidados de saúde, de modo a garantir a satisfação das suas atividades básicas de vida, apoio na reabilitação e reinserção social, superiores aos da população em geral (Benbassat \& Taragin, 2000; Escoval et al., 2010; Halasyamani et al., 2006). Este facto levanta desafios ao SNS, uma vez que Portugal, à semelhança dos restantes países da União Europeia, regista uma percentagem crescente de idosos. Estima-se que entre 2004 e 2050, a percentagem de idosos no total da população portuguesa aumentará de 16,9\% para 31,9\% (Petronilho, 2010).

Aumentar a qualidade dos cuidados prestados ao mesmo tempo que se reduzem custos, ou pelo menos não se aumentem, é sempre um desafio em qualquer empresa ou instituição, mas no sistema de saúde essa gestão torna-se ainda mais evidente e difícil (Jha et al. 2009). A nível Hospitalar esse paradigma é sempre visto com ponderação, pois não é fácil reduzir custos onde se prestam cuidados diferenciados, com recurso a bastante tecnologia, recursos humanos, tudo o que envolve as cirurgias e mesmo as condições hoteleiras (Parker, 2005).

No sentido de intentar atribuir custos de internamento em regime hospitalar é necessário uniformizar o diagnóstico. Com base no estudo da ERS (2015), a casuística nas Unidades de Internamento da RNCCl e mesmo nas $\mathrm{ECCl}$ (domicílio), relativamente ao diagnóstico principal mais frequente é a "doença vascular cerebral aguda, mas mal definida". Assim, relativamente ao custo do/a utente que se encontre hospitalizado, considerando o diagnóstico mais frequente, segundo a classificação de Grupos de Diagnóstico Homogéneos (Portaria no 234/2015 de 07 de agosto; Portaria no 254/2018 de setembro), o valor por dia de internamento varia entre 528,63€ e 1.188,39 €, mediante o nível de severidade.

A RNCCI dispõe de um modelo de financiamento específico, o qual define o financiamento das unidades e equipas, em função das suas condições de funcionamento, podendo incluir comparticipações do MTSSS, MS e dos/as utentes, assumindo-se como um modelo que aposta na diversificação das fontes de financiamento. Os montantes totais dos resultados líquidos dos Jogos Sociais da Santa Casa da Misericórdia de Lisboa são distribuídos segundo os critérios constantes do Decreto-Lei n.o 56/2006, de 15 de março, existindo uma parte das verbas atribuídas ao MS e ao MESS afetas aos cuidados continuados, sendo atualizados periodicamente. A Figura 2 apresenta o financiamento das unidades de internamento da rede durante o período em análise.

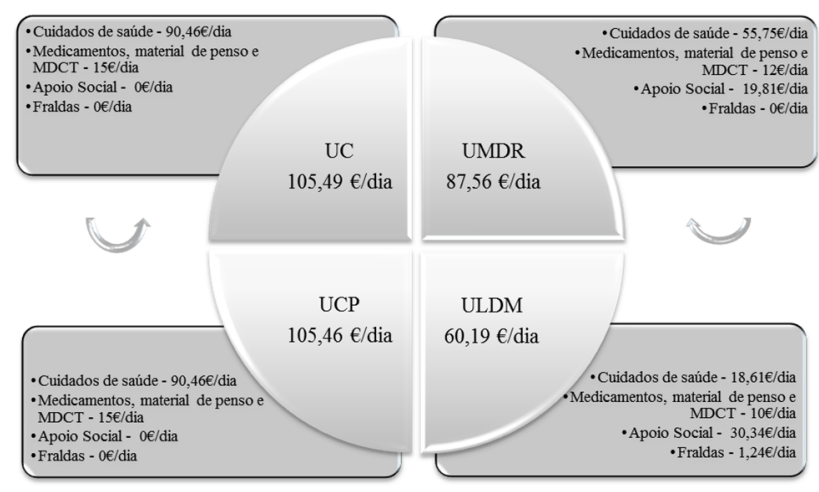

Figura 2- Financiamento das Unidades de Internamento, 2014

Fonte: Adaptado da Portaria no 360 de 16 de dezembro de 2013 
Entretanto, o financiamento das unidades da RNCCI foi sofrendo sucessivas atualizações vigorando, em 2019, os seguintes montantes: 109,09€ para as UC e UCP; 90,57€ para as UMDR; e, 62,25€ para as ULDM (Portaria no 17/2019, de 15 de janeiro de 2019).

O Orçamento de Estado para o Programa de Saúde, no ano de 2015, totalizou 9.803 milhões de euros, perfazendo $8.9 \%$ do Produto Interno Bruto (PIB). De um resultado negativo de -267 Milhões de euros no ano de 2014, o SNS passou para um prejuízo de 408 Milhões de euros no ano em 2015 (ACSS, 2016). Em 2019 o Orçamento de Estado fez mais um reforço das verbas atribuídas ao Programa de Saúde no valor de 10.233 Milhões de euros, representando um acréscimo, relativamente a 2014 , de 4,4\%. (MS, 2018).

Por outro lado, a ACSS (2015b) refere que as despesas públicas em percentagem do PIB afetas a cuidados continuados na União Europeia a 27 países, em 2010, variaram entre os $0,16 \%$ do PIB e os $4,5 \%$ do PIB, tendo Portugal estado entre os países com menor despesa, $0,31 \%$ do PIB.

O valor da execução financeira durante o ano de 2019 foi de 198.710.902,95€, destes 42.208.017,99€ foram assumidos pelo MTSSS e 156.502.884,96€ pelo MS (em 2014 foi de $152.705 .364,97 €, 31.764 .474,54 €$ assumidos pelo MTSSS e 120.940.890,43€ pelo MS) (ACSS, 2015a, 2019). Desde a implementação da RNCCI em 2006 até 2019, o valor global de execução financeira é de 1.759.094.387€, sendo de 80,1\% o valor da componente Saúde. Em termos médios, grande parte das verbas $(74,4 \%)$ são transferidas para pagamento do funcionamento das unidades de internamento e apenas $5,7 \%$ são para investimento em novas unidades ou ampliações das já existentes. O investimento na RNCCI no período 2006-2019 foi acima dos 101 mil milhões de euros (ACSS, 2019).

\section{METODOLOGIA}

Atendendo à problemática, optou-se por desenvolver um estudo quantitativo, não experimental, descritivo, retrospetivo e transversal. Segue-se a descrição dos objetivos e questões de investigação, das variáveis em estudo, da população e obtenção da amostra e da obtenção e tratamento dos dados.

\subsection{Objetivos e Questões de Investigação}

Este estudo tem como objetivo principal analisar o impacto dos processos de referenciação cancelados na $\mathrm{RNCCI}$ na região Norte, mais especificamente:

- Caracterização dos processos de referenciação cancelados para a RNCCI na região Norte em termos de tipologia de Unidades da RNCCl e do motivo de cancelamento;

- Verificar se existem diferenças no tempo de identificação de vaga em função da tipologia de unidade ou motivo de cancelamento;

- Verificar se existem diferenças no tempo de cancelamento da vaga em função da tipologia de unidade ou motivo de cancelamento.

Para uma melhor compreensão do problema em estudo e com vista a delinear um fio condutor, as questões que se pretendem ver respondidas com este trabalho de investigação são:

- Q1 - Quais as características dos processos cancelados na RNCCI na região Norte, em termos de tipologia das Unidades e motivo de cancelamento? 
- Q2 - O tempo de identificação de vaga difere em função da tipologia da Unidade e motivo de cancelamento?

- Q3 - O tempo de cancelamento da vaga difere em função da tipologia da Unidade e motivo de cancelamento?

\subsection{Variáveis em Estudo}

As variáveis dependentes do estudo são o tempo médio de atribuição de vaga e o tempo médio de cancelamento dos processos cancelados da $\mathrm{RNCCl}$ e as variáveis independentes são a tipologia das Unidades da RNCCl e o motivo do cancelamento dos processos. Na Tabela 1 apresentam-se as variáveis em estudo.

Tabela 1 - Variáveis em estudo

\begin{tabular}{lll}
\hline \multicolumn{1}{c}{ Variáveis SPSS } & \multicolumn{1}{c}{ Descrição } & Fonte \\
\hline ID Episódio & Identificação do episódio & ACSS \\
\hline Tipologia & Tipologia da unidade da RNCI & ACSS \\
\hline Motivo de cancelamento da vaga & Motivo de cancelamento & ACSS \\
\hline Chegada ECL & ECL avaliação & ACSS \\
\hline Chegada ECR & ECR para atribuição de vaga & ACSS \\
\hline Data disponibilização vaga & Data da atribuição de vaga & ACSS \\
\hline Data fim reserva & Data do cancelamento & ACSS \\
\hline Tempo de identificação de vaga & Tempo de identificação de vaga & ACSS / Autor \\
\hline Tempo de cancelamento de vaga & Tempo de cancelamento de vaga & ACSS / Autor \\
\hline
\end{tabular}

\subsection{População e Amostra em Estudo}

A população deste estudo é constituída pelos processos referenciados para a $\mathrm{RNCCl}$ ao nível da região Norte, sobre o domínio da ECR Norte, para Unidades da RNCCI implantadas nessa região que foram cancelados após atribuição de vaga, no período de 01 de julho de 2014 e 30 de junho de 2015, num total de 1.563 processos.

Após uma análise à base de dados em formato Excel fornecida pela ACSS, foi necessário retirar todos os episódios de referenciação que apresentavam incongruências de dados, relativamente à data de obtenção de vaga e data de cancelamento, que por vezes era inexistente ou apresentava valores dúbios (tempo de atribuição de vaga superior a 90 dias, diferença entre data de atribuição de vaga e cancelamento maior que 30 dias, data de cancelamento anterior à data de colocação, não sendo o cancelamento por motivo de óbito). Assim, a amostra deste estudo é constituída pelos processos referenciados para a $\mathrm{RNCCl}$ ao nível da região Norte, sobre o domínio da ECR Norte, para Unidades da RNCCI implantadas nessa região que foram cancelados após atribuição de vaga, no período de 01 de julho de 2014 e 30 de junho de 2015 , num total de 1.058 processos.

\subsection{Obtenção e Tratamento de Dados}

Os dados para análise, relativos aos processos de referenciação que ocorreram durante o 20 semestre de 2014 e 1o semestre de 2015 na região Norte, foram extraídos da plataforma 
GESTCARE $\mathrm{CCl}^{\circ}$ (sistema informático dedicado à RNCCI) e facultados pelo Departamento de Contratualização da ARSN - Área Funcional dos Cuidados Continuados Integrados provenientes da entidade gestora nacional da RNCCI, a ACSS.

O tratamento de dados foi efetuado com recurso ao programa informático Statistical Package for the Social Science (SPSS) ${ }^{\oplus}$ da IBM, versão 21 para a análise descritiva e inferencial. Na análise inferencial recorreu-se ao teste paramétrico de Análise da Variância a um fator (ANOVA ONE-WAY) e teste post-hoc HSD de Tukey, para testar diferenças entre diversas situações e para duas ou mais variáveis.

\section{APRESENTAÇÃO E DISCUSSÃO DOS RESULTADOS}

Como podemos verificar na Tabela 2, os processos cancelados representam $11 \%$ do total de processos com atribuição de vaga, os processos admitidos $89 \%$. Verifica-se ainda que o número de processos analisados para a variável 'tempo de cancelamento da vaga' é inferior $(\mathrm{N}=974)$, comparativamente às restantes variáveis, uma vez que alguns utentes faleceram e informaticamente foi atribuída a data de óbito anterior à data de cancelamento da vaga.

Tabela 2 - Processos admitidos e cancelados

\begin{tabular}{lccc}
\hline & $N$ & $\begin{array}{c}\text { Para tempo médio de } \\
\text { identificação de vaga }\end{array}$ & $\begin{array}{c}\text { Para tempo médio de } \\
\text { cancelamento de vaga }\end{array}$ \\
\hline Processos Cancelados & $1.058(11 \%)$ & 1.058 & 974 \\
\hline Processos Admitidos & $8.695(89 \%)$ & - & - \\
\hline
\end{tabular}

No que concerne ao 'motivo de cancelamento da vaga' (Tabela 3), quase metade dos processos foram cancelados por 'agravamento da situação clínica' (44\%), tendo o motivo 'resolução do objetivo terapêutico' a menor frequência $(5,4 \%)$. Os motivos 'recusa de ingresso' por parte do/a utente (15,7\%), cancelamento por 'óbito' (13,7\%) e 'alta clínica' $(11,2 \%)$ apresentam sensivelmente a mesma distribuição na amostra.

Na classificação "outra" não foi possível apurar qual o verdadeiro motivo do cancelamento, no entanto, pode-se tentar atribuir este resultado ao registo deficitário do profissional que cancelou o processo, existindo vários estudos que suportam a importância dos registos, as novas plataformas tecnológicas e também a importância de informar e formar os profissionais para que os registos sejam elaborados da forma mais correta e com que objetivos (Pestana, 2007; Sousa, 2006; Goossen, 2000).

Tabela 1 - Motivo de cancelamento da vaga

\begin{tabular}{lcc}
\hline \multicolumn{1}{c}{ Motivo de Cancelamento } & Frequência & \% válida \\
Recusa de ingresso na RNCCl & 166 & 15,7 \\
Agravamento da situação clínica & 466 & 44,0 \\
Alta Clínica & 118 & 11,2 \\
Resolução do objetivo terapêutico & 57 & 5,4 \\
Óbito & 145 & 13,7 \\
Outra & 106 & 10,0 \\
Total & 1.058 & 100,0 \\
\hline
\end{tabular}

Por sua vez, no que diz respeito à tipologia da unidade (Tabela 4), as percentagens de processos cancelados estão muito próximas para praticamente todas as tipologias, exceto no 
que se refere à UCP, que apresenta uma percentagem de processos consideravelmente inferior $(3,1 \%)$.

Tabela 2 - Processos cancelados por tipologia da unidade

\begin{tabular}{lcc}
\hline \multicolumn{1}{c}{ Tipologia da Unidade } & Frequência & \% válida \\
\hline ECCI - Equipa de Cuidados Continuados Integrados & 300 & 28,4 \\
UC - Unidade de Convalescença & 277 & 26,2 \\
UMDR - Unidade de Média Duração e Reabilitação & 232 & 21,9 \\
ULDM - Unidade de Longa Duração e Manutenção & 216 & 20,4 \\
UCP - Unidade de Cuidados Paliativos & 33 & 3,1 \\
Total & 1.058 & 100,0 \\
\hline
\end{tabular}

O tempo médio de identificação de vaga nos processos cancelados é de 10,61 dias, apresentando uma amplitude bastante considerável [0,01 dias - 63,75 dias]. Relativamente ao tempo médio de cancelamento de vaga, este é de 1,42 dias, com uma amplitude entre 0 dias e 8,35 dias (Tabela 5).

Tabela 5 - Tempo médio de identificação e cancelamento de vaga

\begin{tabular}{lcccc}
\cline { 2 - 5 } & $\mathbf{N}$ & Intervalo & Média & DP \\
\hline Tempo de Identificação de Vaga (dias) & 1.058 & $0,01-63,75$ & 10,61 & 11,71 \\
\hline Tempo de Cancelamento de Vaga (dias) & 974 & $0,00-8,35$ & 1,42 & 1,34 \\
\hline
\end{tabular}

No sentido de verificar a existência de diferenças significativas no Tempo Médio de Identificação de Vaga pelas diferentes Tipologias, procedeu-se à realização de uma análise da variância (ANOVA ONE-WAY) seguida do teste post-hoc HSD de Tukey.

Os resultados apresentados nas tabelas 6 e 7 demonstram que existem diferenças estatisticamente significativas entre os grupos $(F=115,232 ; p<0,001)$, mais concretamente entre a tipologia $\mathrm{ECCl}$ (4,71 dias) e as tipologias UC ( 9,52 dias), UMDR (22,28 dias) e ULDM (8,41 dias); entre a tipologia UC (9,52 dias) e a tipologia UMDR (22,28 dias); e, entre a tipologia UMDR (22,28 dias) e as tipologias ULDM (8,41 dias) e UCP (5,78 dias).

Tabela 6 - Tempo médio de identificação da vaga/Tipologia da unidade (ANOVA)

\begin{tabular}{lcccccc} 
& ECCI & UC & UMDR & ULDM & UCP & F \\
\hline $\begin{array}{l}\text { Tempo Médio de Identificação da Vaga } \\
\text { (dias) }\end{array}$ & 4,71 & 9,52 & 22,28 & 8,41 & 5,78 & $115,232^{* * *}$ \\
\hline Noła: ${ }^{* * *} p<0,001$ & & & & &
\end{tabular}

Tabela 7 - Tempo médio de identificação da vaga/Tipologia da unidade (Comparação Múltipla de Médias)

\begin{tabular}{|c|c|c|c|c|c|c|}
\hline \multirow{2}{*}{$\begin{array}{c}\text { Tipologia da } \\
\text { Unidade } \\
\text { I }\end{array}$} & \multirow{2}{*}{$\begin{array}{l}\text { Tipologia da } \\
\text { Unidade } \\
\text { J }\end{array}$} & \multirow{2}{*}{$\begin{array}{l}\text { Diferença } \\
\text { Média } \\
(1-J)\end{array}$} & \multirow[b]{2}{*}{$\begin{array}{l}\text { Erro } \\
\text { Padrão }\end{array}$} & \multirow[b]{2}{*}{ Sig. } & \multicolumn{2}{|c|}{ Intervalo Confiança 95\% } \\
\hline & & & & & $\begin{array}{l}\text { Limite } \\
\text { Inferior }\end{array}$ & $\begin{array}{l}\text { Limite } \\
\text { Superior }\end{array}$ \\
\hline \multirow{4}{*}{$\mathrm{ECCl}$} & UC & $-4,81609^{*}$ & ,81544 &, 000 & $-7,0443$ & $-2,5879$ \\
\hline & UMDR & $-17,56325^{*}$ & 85557 &, 000 & $-19,9011$ & $-15,2254$ \\
\hline & ULDM & $-3,70352^{*}$ & ,87326 &, 000 & $-6,0897$ & $-1,3173$ \\
\hline & UCP & $-1,06526$ & 1,79477 & 976 & $-5,9695$ & 3,8390 \\
\hline \multirow{4}{*}{ UC } & $\mathrm{ECCl}$ & $4,81609^{*}$ & 81544 &, 000 & 2,5879 & 7,0443 \\
\hline & UMDR & $-12,74716^{*}$ & ,87092 &, 000 & $-15,1270$ & $-10,3674$ \\
\hline & ULDM & 1,11257 & 88830 & ,720 & $-1,3147$ & 3,5399 \\
\hline & UCP & 3,75083 & 1,80214 & .229 & $-1,1735$ & 8,6752 \\
\hline
\end{tabular}




\begin{tabular}{lllllll}
\hline \multirow{4}{*}{ UMDR } & ECCI & $17,56325^{*}$ &, 85557 &, 000 & 15,2254 & 19,9011 \\
\cline { 2 - 6 } & UC & $12,74716^{*}$ &, 87092 &, 000 & 10,3674 & 15,1270 \\
\cline { 2 - 6 } & ULDM & $13,85973^{*}$ &, 92528 &, 000 & 11,3314 & 16,3881 \\
\cline { 2 - 6 } & UCP & $16,49799^{*}$ & 1,82065 &, 000 & 11,5230 & 21,4729 \\
\hline \multirow{3}{*}{ ULDM } & ECCI & $3,70352^{*}$ &, 87326 &, 000 & 1,3173 & 6,0897 \\
\cline { 2 - 6 } & UC & $-1,11257$ &, 88830 &, 720 & $-3,5399$ & 1,3147 \\
\cline { 2 - 6 } & UMDR & $-13,85973^{*}$ &, 92528 &, 000 & $-16,3881$ & $-11,3314$ \\
\cline { 2 - 6 } & UCP & 2,63825 & 1,82903 &, 600 & $-2,3596$ & 7,6361 \\
\hline \multirow{3}{*}{ UCP } & ECCI & 1,06526 & 1,79477 &, 976 & $-3,8390$ & 5,9695 \\
\cline { 2 - 6 } & UC & $-3,75083$ & 1,80214 &, 229 & $-8,6752$ & 1,1735 \\
\cline { 2 - 6 } & UMDR & $-16,49799^{*}$ & 1,82065 &, 000 & $-21,4729$ & $-11,5230$ \\
\cline { 2 - 6 } & ULDM & $-2,63825$ & 1,82903 &, 600 & $-7,6361$ & 2,3596 \\
\hline
\end{tabular}

Nota: * A diferença média é significativa no nível 0,001

Relativamente ao Tempo Médio de Identificação de Vaga em função do Motivo de Cancelamento, pela observação das Tabelas 8 e 9, demonstra-se a existência de diferenças estatisticamente significativas entre os grupos $(F=14,222 ; p<0,001)$, mais concretamente entre a 'alta clínica' (16,58 dias) e o 'agravamento da situação clínica' (7,79 dias) e 'outra' (10,13 dias); entre 'recusa de ingresso na rede' (12,32 dias) e 'agravamento da situação clínica' (7,79 dias); e, entre 'agravamento da situação clínica' (7,79 dias) e 'óbito' (12,18 dias). 0 tempo médio mais elevado encontra-se em 'alta clínica' (16,58 dias), ou seja, poderia ter deixado de ser necessário recorrer ao internamento na $\mathrm{RNCCl}$, em sentido oposto encontramos o 'agravamento da situação clínica' (7,79 dias).

Tabela 8 - Tempo médio de identificação da vaga/Motivo de cancelamento (ANOVA)

\begin{tabular}{lcc}
\hline \multicolumn{1}{c}{ Motivo de Cancelamento } & Tempo Médio de Identificação da Vaga (dias) & F \\
\hline Recusa de ingresso na RNCCI & 12,32 & \\
Agravamento da situação clínica & 7,79 & $14,222^{* * *}$ \\
Alta clínica & 16,58 & \\
Resolução do objetivo terapêutico & 13,26 & \\
Óbito & 12,18 & \\
Outra & 10,13 & \\
\hline Nota: ${ }^{* * *} \mathrm{p}<0,001$ & &
\end{tabular}

Tabela 9 - Tempo médio de identificação da vaga/Motivo de cancelamento (Comparação Múltipla de Médias)

\begin{tabular}{|c|c|c|c|c|c|c|}
\hline \multirow{2}{*}{$\begin{array}{c}\text { Motivo de } \\
\text { Cancelament } \\
\text { ol }\end{array}$} & \multirow{2}{*}{ Motivo de Cancelamento } & \multirow{2}{*}{$\begin{array}{l}\text { Diferença Média } \\
(I-J)\end{array}$} & \multirow{2}{*}{$\begin{array}{l}\text { Erro } \\
\text { Padrão }\end{array}$} & \multirow{2}{*}{ Sig. } & \multicolumn{2}{|c|}{ Intervalo Confiança 95\% } \\
\hline & & & & & Limite Inferior & Limite Superior \\
\hline \multirow{5}{*}{ Alta Clínica } & $\begin{array}{l}\text { Resolução do objetivo } \\
\text { terapêutico }\end{array}$ & 3,31387 & 1,83268 & ,461 & $-1,9184$ & 8,5461 \\
\hline & Recusa de ingresso na RNCCI & 4,25486 & 1,36808 & .024 & 3490 & 8,1607 \\
\hline & Agravamento da situação clínica & $8,78789^{*}$ & 1,17090 & .000 & 5,4450 & 12,1308 \\
\hline & Óbito & 4,39536 & 1,40864 & .023 & 3737 & 8,4170 \\
\hline & Outra & $6,44272^{*}$ & 1,52047 & .000 & 2,1018 & 10,7836 \\
\hline \multirow{5}{*}{$\begin{array}{l}\text { Resolução do } \\
\text { objetivo } \\
\text { terapêutico }\end{array}$} & Alta Clínica & $-3,31387$ & 1,83268 & 461 & $-8,5461$ & 1,9184 \\
\hline & Recusa de ingresso na RNCCl & 94099 & 1,74425 & 995 & $-4,0388$ & 5,9208 \\
\hline & Agravamento da situação clínica & 5,47402 & 1,59429 & .008 & 9224 & 10,0257 \\
\hline & Óbito & 1,08149 & 1,77624 & .990 & $-3,9896$ & 6,1526 \\
\hline & Outra & 3,12885 & 1,86617 & ,548 & $-2,1990$ & 8,4567 \\
\hline \multirow{5}{*}{$\begin{array}{l}\text { Recusa de } \\
\text { ingresso na } \\
\text { RNCCl }\end{array}$} & Alta Clínica & $-4,25486$ & 1,36808 & .024 & $-8,1607$ &,- 3490 \\
\hline & $\begin{array}{l}\text { Resolução do objetivo } \\
\text { terapêutico }\end{array}$ &,- 94099 & 1,74425 & ,995 & $-5,9208$ & 4,0388 \\
\hline & Agravamento da situação clínica & $4,53303^{*}$ & 1,02697 & .000 & 1,6010 & 7,4650 \\
\hline & Óbito & .14050 & 1,29148 & 1,000 & $-3,5467$ & 3,8277 \\
\hline & Outra & 2,18786 & 1,41262 & .633 & $-1,8451$ & 6,2208 \\
\hline
\end{tabular}




\begin{tabular}{|c|c|c|c|c|c|c|}
\hline \multirow{5}{*}{$\begin{array}{l}\text { Agravamento } \\
\text { da situação } \\
\text { clínica }\end{array}$} & Alta Clínica & $-8,78789^{*}$ & 1,17090 &, 000 & $-12,1308$ & $-5,4450$ \\
\hline & $\begin{array}{l}\text { Resolução do objetivo } \\
\text { terapêutico }\end{array}$ & $-5,47402$ & 1,59429 & .008 & $-10,0257$ &,- 9224 \\
\hline & Recusa de ingresso na RNCCl & $-4,53303^{*}$ & 1,02697 & .000 & $-7,4650$ & $-1,6010$ \\
\hline & Óbito & $-4,39252^{*}$ & 1,08041 & .001 & $-7,4771$ & $-1,3080$ \\
\hline & Outra & $-2,34517$ & 1,22264 &, 392 & $-5,8358$ & 1,1454 \\
\hline \multirow{5}{*}{ Óbito } & Alta Clínica & $-4,39536$ & 1,40864 &, 023 & $-8,4170$ &,- 3737 \\
\hline & $\begin{array}{l}\text { Resolução do objetivo } \\
\text { terapêutico }\end{array}$ & $-1,08149$ & 1,77624 & 990 & $-6,1526$ & 3,9896 \\
\hline & Recusa de ingresso na RNCCl &,- 14050 & 1,29148 & 1,000 & $-3,8277$ & 3,5467 \\
\hline & Agravamento da situação clínica & $4,39252^{*}$ & 1,08041 & 001 & 1,3080 & 7,4771 \\
\hline & Outra & 2,04736 & 1,45193 &, 721 & $-2,0979$ & 6,1926 \\
\hline \multirow{5}{*}{ Outra } & Alta Clínica & $-6,44272^{*}$ & 1,52047 &, 000 & $-10,7836$ & $-2,1018$ \\
\hline & $\begin{array}{l}\text { Resolução do objetivo } \\
\text { terapêutico }\end{array}$ & $-3,12885$ & 1,86617 &, 548 & $-8,4567$ & 2,1990 \\
\hline & Recusa de ingresso na RNCCl & $-2,18786$ & 1,41262 &, 633 & $-6,2208$ & 1,8451 \\
\hline & Agravamento da situação clínica & 2,34517 & 1,22264 &, 392 & $-1,1454$ & 5,8358 \\
\hline & Óbito & $-2,04736$ & 1,45193 &, 721 & $-6,1926$ & 2,0979 \\
\hline
\end{tabular}

Nota: * A diferença média é significativa no nível 0,001

Relativamente ao Tempo Médio de Cancelamento de Vaga em função da Tipologia, pela observação das Tabela 10 e 11 demonstra-se a existência de diferenças estatisticamente significativas entre os grupos $(F=9,496 ; p<0,001)$, mas apenas entre a tipologia $\mathrm{ECCl}(1,75$ dias) e a tipologia UC (1,09 dias).

Tabela 10 - Tempo médio de cancelamento da vaga/Tipologia da unidade (ANOVA)

\begin{tabular}{lcccccc}
\cline { 2 - 6 } & ECCI & UC & UMDR & ULDM & UCP & F \\
\hline $\begin{array}{l}\text { Tempo Médio de Cancelamento de Vaga } \\
\text { (dias) }\end{array}$ & 1,75 & 1,09 & 1,40 & 1,51 & 1,49 & $9,496^{* * *}$ \\
\hline Nota: ${ }^{* * *} p<.001$ & & & & & &
\end{tabular}

Tabela 11 - Tempo médio de cancelamento da vaga/Tipologia da unidade (Comparação Múltipla de Médias)

\begin{tabular}{|c|c|c|c|c|c|c|}
\hline \multirow{2}{*}{$\begin{array}{c}\text { Tipologia da } \\
\text { Unidade } \\
\text { I }\end{array}$} & \multirow{2}{*}{$\begin{array}{c}\text { Tipologia da } \\
\text { Unidade } \\
\text { J }\end{array}$} & \multirow{2}{*}{$\begin{array}{l}\text { Diferença } \\
\text { Média }(I-J)\end{array}$} & \multirow{2}{*}{$\begin{array}{c}\text { Erro } \\
\text { Padrão }\end{array}$} & \multirow[b]{2}{*}{ Sig. } & \multicolumn{2}{|c|}{ Intervalo Confiança 95\% } \\
\hline & & & & & $\begin{array}{l}\text { Limite } \\
\text { Inferior }\end{array}$ & $\begin{array}{c}\text { Limite } \\
\text { Superior }\end{array}$ \\
\hline \multirow{4}{*}{$\mathrm{ECCl}$} & UC & $67192^{\circ}$ & ,11154 &, 000 & ,3671 &, 9767 \\
\hline & UMDR &, 41705 & , 11893 &, 004 & 0920 & ,7421 \\
\hline & ULDM & ,24742 & , 12447 & 273 &,- 0927 &, 5876 \\
\hline & UCP & ,27011 & ,36088 & ,945 &,- 7161 & 1,2564 \\
\hline \multirow{4}{*}{ UC } & $\mathrm{ECCl}$ &,$- 67192^{\circ}$ & ,11154 &, 000 &,- 9767 &,- 3671 \\
\hline & UMDR &,- 25487 & , 11995 &, 210 &,- 5827 & 0729 \\
\hline & ULDM &,- 42450 &, 12545 & .007 &,- 7673 &,- 0817 \\
\hline & UCP &,- 40181 & ,36122 &, 800 & $-1,3890$ &, 5854 \\
\hline \multirow{4}{*}{ UMDR } & $\mathrm{ECCl}$ &,- 41705 &, 11893 &, 004 &,- 7421 &,- 0920 \\
\hline & UC &, 25487 & , 11995 &, 210 &,- 0729 &, 5827 \\
\hline & ULDM &,- 16963 &, 13206 & ,701 &,- 5305 &, 1913 \\
\hline & UCP &,- 14694 & 36357 & 994 & $-1,1405$ & ,8467 \\
\hline \multirow{4}{*}{ ULDM } & $\mathrm{ECCl}$ &,- 24742 &, 12447 &, 273 &,- 5876 & 0927 \\
\hline & UC &, 42450 & , 12545 & ,007 & ,0817 & ,7673 \\
\hline & UMDR & ,16963 & ,13206 & ,701 &,- 1913 &, 5305 \\
\hline & UCP &, 02269 &, 36542 & 1,000 &,- 9760 & 1,0214 \\
\hline \multirow{4}{*}{ UCP } & $\mathrm{ECCl}$ &,- 27011 & ,36088 & ,945 & $-1,2564$ & .7161 \\
\hline & UC & ,40181 &, 36122 & 800 &,- 5854 & 1,3890 \\
\hline & UMDR &, 14694 &, 36357 & ,994 &,- 8467 & 1,1405 \\
\hline & ULDM &,- 02269 &, 36542 & 1,000 & $-1,0214$ & 9760 \\
\hline
\end{tabular}

Nota: * A diferença média é significativa no nível 0,001 
Em relação ao Tempo Médio de Cancelamento de Vaga em função do Motivo de Cancelamento, pela observação das Tabelas 12 e 13 demonstra-se também a existência de diferenças estatisticamente significativas entre os grupos $(F=10,777 ; p<0,001)$, mais concretamente entre a 'alta clínica' (0,84 dias) e o 'agravamento da situação clínica' (1,71 dias); entre 'resolução do objetivo terapêutico' (1,11 dias) e 'agravamento da situação clínica' (1,71 dias); e, entre 'recusa de ingresso na rede' (1,20 dias) e 'agravamento da situação clínica' (1,71 dias).

Tabela 12 - Tempo médio de cancelamento da vaga/Motivo de cancelamento (ANOVA)

\begin{tabular}{lcc}
\hline \multicolumn{1}{c}{ Motivo de Cancelamento } & $\begin{array}{c}\text { Tempo Médio de Cancelamento da vaga } \\
\text { (dias) }\end{array}$ & F \\
\hline Recusa do utente em ingressar na RNCCl & 1,20 & \\
Agravamento da situação clínica & 1,71 & $10,777^{* * *}$ \\
Alta Clínica & 0,84 & \\
Resolução do objetivo terapêutico & 1,11 & \\
Óbito & 1,28 & \\
Outra & 1,44 &
\end{tabular}

Tabela 13. Tempo médio de cancelamento da vaga/Motivo de cancelamento (Comparação Múltipla de Médias)

\begin{tabular}{|c|c|c|c|c|c|c|}
\hline \multirow{2}{*}{$\begin{array}{l}\text { Motivo de } \\
\text { Cancelamento } \\
\text { I }\end{array}$} & \multirow{2}{*}{$\begin{array}{l}\text { Motivo de } \\
\text { Cancelamento } \\
\text { J }\end{array}$} & \multirow{2}{*}{$\begin{array}{l}\text { Diferença } \\
\text { Média (I-J) }\end{array}$} & \multirow{2}{*}{$\begin{array}{c}\text { Erro } \\
\text { Padrão }\end{array}$} & \multirow[b]{2}{*}{ Sig. } & \multicolumn{2}{|c|}{ Intervalo Confiança 95\% } \\
\hline & & & & & $\begin{array}{l}\text { Limite } \\
\text { Inferior }\end{array}$ & $\begin{array}{l}\text { Limite } \\
\text { Superior }\end{array}$ \\
\hline \multirow{5}{*}{ Alta Clínica } & $\begin{array}{l}\text { Resolução do objetivo } \\
\text { terapêutico }\end{array}$ &,- 27146 & ,21109 & ,793 &,- 8742 & ,3313 \\
\hline & $\begin{array}{l}\text { Recusa de ingresso na } \\
\text { RNCCl }\end{array}$ &,- 35798 & , 15758 & ,207 &,- 8079 & ,0920 \\
\hline & $\begin{array}{l}\text { Agravamento da } \\
\text { situação clínica }\end{array}$ &,- 86472 & ,13486 &, 000 & $-1,2498$ &,- 4796 \\
\hline & Óbito &,- 44177 & ,20637 &, 267 & $-1,0310$ & ,1475 \\
\hline & Outra &,- 60188 & , 17513 & ,008 & $-1,1019$ &,- 1018 \\
\hline \multirow{5}{*}{$\begin{array}{l}\text { Resolução do } \\
\text { objetivo } \\
\text { terapêutico }\end{array}$} & Alta Clínica &, 27146 &, 21109 &, 793 &,- 3313 &, 8742 \\
\hline & $\begin{array}{l}\text { Recusa de ingresso na } \\
\mathrm{RNCCl}\end{array}$ & -,08652 & ,20090 & ,998 &,- 6602 & 4871 \\
\hline & $\begin{array}{l}\text { Agravamento da } \\
\text { situação clínica }\end{array}$ &,$- 59326^{\circ}$ & ,18363 &, 016 & $-1,1176$ &,- 0689 \\
\hline & Óbito &,- 17031 &, 24108 &, 981 &,- 8587 &, 5181 \\
\hline & Outra &,- 33042 &, 21495 &, 640 &,- 9442 &, 2833 \\
\hline \multirow{5}{*}{$\begin{array}{l}\text { Recusa de } \\
\text { ingresso na } \\
\mathrm{RNCCl}\end{array}$} & Alta Clínica &, 35798 & , 15758 & ,207 &,- 0920 & ,8079 \\
\hline & $\begin{array}{l}\text { Resolução do objetivo } \\
\text { terapêutico }\end{array}$ & ,08652 & ,20090 & ,998 &,- 4871 & ,6602 \\
\hline & $\begin{array}{l}\text { Agravamento da } \\
\text { situação clínica }\end{array}$ &,$- 50674^{*}$ &, 11829 &, 000 &,- 8445 &,- 1690 \\
\hline & Óbito &,- 08379 &, 19594 & ,998 &,- 6433 &, 4757 \\
\hline & Outra &,- 24390 &, 16271 &, 665 &,- 7085 &, 2207 \\
\hline \multirow{5}{*}{$\begin{array}{l}\text { Agravamento } \\
\text { da situação } \\
\text { clínica }\end{array}$} & Alta Clínica &, $86472^{\circ}$ & ,13486 &, 000 & ,4796 & 1,2498 \\
\hline & $\begin{array}{l}\text { Resolução do objetivo } \\
\text { terapêutico }\end{array}$ &, 59326 & , 18363 & ,016 & ,0689 & 1,1176 \\
\hline & $\begin{array}{l}\text { Recusa de ingresso na } \\
\text { RNCCl }\end{array}$ &, $50674^{*}$ &, 11829 & ,000 & , 1690 & ,8445 \\
\hline & Óbito & ,42295 & ,17819 & ,167 &,- 0858 & ,9317 \\
\hline & Outra & ,26284 & ,14082 &, 424 &,- 1393 & ,6650 \\
\hline \multirow{4}{*}{ Óbito } & Alta Clínica &, 44177 & ,20637 &, 267 &,- 1475 & 1,0310 \\
\hline & $\begin{array}{l}\text { Resolução do objetivo } \\
\text { terapêutico }\end{array}$ & , 17031 &, 24108 & ,981 &,- 5181 & ,8587 \\
\hline & $\begin{array}{l}\text { Recusa de ingresso na } \\
\text { RNCCl }\end{array}$ & ,08379 & 19594 & ,998 &,- 4757 &, 6433 \\
\hline & $\begin{array}{l}\text { Agravamento da } \\
\text { situação clínica }\end{array}$ &,- 42295 & ,17819 & , 167 &,- 9317 & ,0858 \\
\hline
\end{tabular}




\begin{tabular}{|c|c|c|c|c|c|c|}
\hline & Outra &,- 16011 & ,21031 & ,974 &,- 7606 & ,4404 \\
\hline \multirow{5}{*}{ Outra } & Alta Clínica & ,60188 & , 17513 & ,008 & ,1018 & 1,1019 \\
\hline & $\begin{array}{l}\text { Resolução do objetivo } \\
\text { terapêutico }\end{array}$ & ,33042 & ,21495 &, 640 &,- 2833 &, 9442 \\
\hline & $\begin{array}{l}\text { Recusa de ingresso na } \\
\text { RNCCl }\end{array}$ & ,24390 &, 16271 &, 665 &,- 2207 & ,7085 \\
\hline & $\begin{array}{l}\text { Agravamento da } \\
\text { situação clínica }\end{array}$ &,- 26284 & , 14082 &, 424 &,- 6650 & ,1393 \\
\hline & Óbito & , 16011 & ,21031 &, 974 &,- 4404 & ,7606 \\
\hline
\end{tabular}

Nota: * A diferença média é significativa no nível 0,05

O tempo de cancelamento da vaga é superior quando o motivo é o 'agravamento da situação clínica' (1,71 dias) e inferior nas situações de 'alta clínica' ( 0,84 dias). Este resultado pode ser explicado, pela necessidade resultante da articulação da EGA e/ou ER com a restante equipa médica que acompanha o/a utente, no sentido de aferir se a condição clínica se encontra estabilizada para ingresso na RNCCI, ou seja, um processo de decisão. No caso oposto, surge a 'alta clínica' (0,84 dias), podendo esta ocorrer em simultâneo com o ingresso na RNCCI, mas dado o valor, em média, ultrapassar 12 horas, pode-se estar perante uma situação que o/a utente já teve alta clínica e a EGA (hospital) não teve conhecimento.

Importa ainda referir que, durante o cancelamento de vaga, a cama existente na Unidade da $\mathrm{RNCCl}$ encontra-se "bloqueada" para outro ingresso (utente). Mais, o/a mesmo/a utente caso se encontre internado/a em hospital ocupa virtualmente duas camas (Hospital e RNCCI), em simultâneo. O/A utente que se encontrava imediatamente abaixo na listagem de disponibilização de vaga para essa unidade fica em espera esse tempo. Caso essa vaga/cama não estivesse "bloqueada", o tempo de cancelamento tenderia para inexistente e, consequentemente este/esta mesmo/a utente teria o seu ingresso antecipado, e a lista de espera diminuída. Neste pressuposto, o tempo médio de atribuição de vaga de 8,15 dias para os processos com ingresso na $\mathrm{RNCCI}$ poderia diminuir para 6,73 dias.

\section{IMPLICAÇÕES FINANCEIRAS DOS RESULTADOS DO ESTUDO}

Relativamente ao impacto dos resultados aqui analisados para as Unidades da RNCCI, podese referir que, após a colocação do/a utente via aplicativo informático, a vaga fica ocupada não podendo ser utilizada por outro/a utente. No entanto, a unidade só pode ser remunerada após o ingresso efetivo do/a utente. Assim, apenas para efetuar uma simulação de caráter meramente informativo, tendo em conta o pagamento diário em UC de 105,46€ (Figura 2) por utente colocado/a, a unidade deixa de receber $150 €(105,46 € \times 1,42$ dias), aproximadamente, ou relativamente a uma ULDM $(60,19 € / d i a)$, a unidade deixa de poder receber a verba diária de $85,5 €(60,19 € \times 1,42$ dias $)$. Em termos médios o valor diário das unidades de internamento é de $89,7 €$. Numa tentativa de calcular o custo médio do cancelamento do ingresso na RNCCI estima-se facilmente um custo médio anual de 134.762€ (cálculo com base na média de pagamento $(89,7 €) \times$ tempo médio de colocação $(1,42$ dias $)$ x no de casos aqui apresentados (1.058)).

Em relação à origem da referenciação de utentes em 2019, maioritariamente, provêm das Unidades Hospitalares, representando $63,2 \%$, valor ligeiramente inferior aos $65 \%$ verificados em 2014. Daqui, pode-se também aferir custos derivados dos tempos de espera para ingressar na RNCCI. Considerando o tempo médio de identificação de vaga (10,61 dias), juntamente 
com o tempo médio de colocação na RNCCI (1,42 dias), obtém-se um tempo de espera total de 12,03 dias ACSS (2015a, 2019). Utilizando o diagnóstico principal de utentes que ingressam na RNCCl (ERS, 2015), considerando o valor mínimo de 528,63€ por dia de internamento, o gasto por utente que aguarda ingresso na $\mathrm{RNCCl}$ ascende a cerca de $6.359 €$. Tendo em conta estes resultados, os 688 utentes $(65 \% \times 1.058$ utentes) a aguardar em cama hospitalar, representariam um custo de $4.374 .992 €$ para as unidades hospitalares. Por sua vez, utilizando o mesmo tempo (12,03 dias) mas, em unidades da RNCCI $(89,7 €)$, o custo reduziria substancialmente para 742.414,608€, representado apenas $17 \%$ da verba consumida em internamento hospitalar.

Considerando ainda, que a nível nacional foram assistidos cerca de 45.768 utentes no ano de 2014 (ACSS, 2015a), e destes 29.749 (65\%) encontrar-se-iam internados em regime hospitalar, os custos relativos ao tempo médio de espera (12,03 dias) para ingressar na RNCCI poderiam ultrapassar os 189 milhões de euros, sendo que o mesmo tempo em Unidades da RNCCI implicaria uma transferência de verba do Estado de cerca 32,1 milhões de euros, o que é substancialmente inferior.

Não obstante a importância destes montantes para as Unidades da RNCCI, sem dúvida que o custo mais elevado seja para o/a utente, com impacto ao nível do seu plano de recuperação ou da necessidade de prestação de cuidados. A isto, acresce o facto de ficar internado em regime Hospitalar. Neste caso, os custos aumentam substancialmente, quer a nível económico, social ou mesmo clínico, implicando uma maior taxa de ocupação das camas hospitalares, aumento do número de dias de internamento hospitalar, contribuindo também para um maior risco de infeções hospitalares.

Os valores apresentados, embora não sendo vinculativos e reportando a 2014-2015, não deixam de salientar a importância de uma gestão eficiente do processo de referenciação/ingresso na $\mathrm{RNCCl}$, dadas as consequências reais no agravamento da economia portuguesa, concretamente ao nível do orçamento na área da Saúde.

\section{CONCLUSÃO}

A RNCCl é um parceiro inquestionável na prestação de cuidados de saúde no SNS português, que tem vindo a aumentar a sua capacidade de resposta desde a sua implementação em 2006 , sendo que nesse mesmo ano um dos pontos na agenda política nacional era a sua expansão. Ainda assim, segundo os vários relatórios das entidades fiscalizadoras próprias e externas, ainda não oferece uma resposta comparável com a procura e necessidade, facilmente comprovável pelos tempos médios de espera de atribuição de vaga de 8,15 dias, apresentados neste trabalho para utentes admitidos/as na região Norte durante o período em análise. Segundo a ACSS (2015a), relativamente ao ano de 2014, a nível nacional, o tempo total de todo o processo de referenciação encontra-se em 17 dias (média das medianas apresentadas), com assimetrias regionais, chegando a atingir os 25 dias na região de Lisboa e Vale do Tejo. Atualmente, este cenário agravou-se, pois a média das medianas da RNCCI Geral em 2019 foi de 19,9 dias, mantendo-se as assimetrias regionais, chegando a atingir os 44,5 dias no Alentejo (ACSS, 2019).

Relativamente às questões financeiras, quando envolvidos utentes que aguardam colocação em hospital (4.374.992€), pode-se afirmar que a poupança de recursos financeiros é bastante evidente, apontando este estudo para uma diminuição de custos a rondar os $83 \%$, caso não existissem os tempos de espera (12,03 dias) e o/a utente pudesse ingressar de imediato nas 
Unidades da RNCCI após a atribuição de vaga, pois nestas unidades o custo relativamente a esse tempo seria de $742.414,608 €$. Para as Unidades da RNCCI, considerando o tempo médio de cancelamento do processo após atribuição de vaga, representa um valor que pode ascender aos 134.762€. Segundo Rego \& Nunes (2010), a sustentabilidade financeira do SNS depende substancialmente de uma boa gestão em detrimento de um aumento absoluto dos recursos financeiros.

A existência de processos cancelados após atribuição de vaga (11\%) contribui de forma inequívoca para o aumento do tempo total no processo de referenciação. Veja-se o caso da existência de processos (85) com atribuição de vaga ao/à utente quando este/esta já tinha falecido. Isto pressupõe uma falha de comunicação dentro da EGA Hospitalar ou ER do Centro de Saúde com a restante equipa multidisciplinar que acompanha o/a utente, pelo que se propõe uma revisão nos procedimentos de atuação da equipa EGA/ER, no sentido de supervisionar as alterações da situação clínica de utentes em processo de referenciação e uma maior integração dos sistemas informáticos (nomeadamente ao nível do acesso em tempo real à informação) das organizações envolvidas na RNCCl.

Foi possivel confirmar o impacto dos processos cancelados na RNCCI na região Norte, nomeadamente o aumento do tempo médio de disponibilização de vaga, com o consequente aumento no tempo total de referenciação (elaboração do processo até a entrada do/a utente em unidades da RNCCl) e aumento do número de utentes a aguardar vaga para ingresso, diminuindo assim a eficiência e eficácia deste recurso, com implicações para o/a utente (caso se encontrem no seu domicílio verão afetado o início do seu tratamento/programa de reabilitação ou a prestação de cuidados necessários; aumentada a possibilidade de não ingressar na Unidade de 1a preferência; aumentado o tempo de internamento hospitalar), para o Hospital (aumento dos dias de internamento do/a utente; aumento dos gastos com esse internamento), para as Unidades da RNCCl (diminuição da łaxa de ocupação; diminuição da receita) e para o Estado (aumento da despesa, via transferência de verbas para os hospitais). "A questão da eficiência e eficácia do SNS, mais do que uma questão meramente orçamental, ou até apenas económica, é uma questão ética, ou seja, se o SNS não for eficiente, jamais poderá ser justo e flexível" (Sousa, 2009, p. 888).

Finalmente espera-se que os resultados deste estudo sirvam não só para fundamentar outras pesquisas baseadas na evidência científica sobre a problemática em análise, mas efetivamente para uma maior consciencialização da necessidade de se criarem mecanismos a nível da ECL, no sentido da diminuição do tempo de cancelamento dos processos após atribuição de vaga, através de uma melhor articulação com as ER, principalmente as EGA a nível hospitalar.

Apesar deste estudo se reportar ao período de 2014-2015, a sua pertinência é bem atual, tendo em conta que os dados mais recentes (ACSS, 2019) mostram um agravamento dos tempos de atribuição de vaga em todas as tipologias da RNCCI geral e também do número de casos cancelados, que muito contribuem para a efetivação da colocação de utentes nas unidades da RNCCl.

\section{AGRADECIMENTOS}

Esta pesquisa científica que aqui se relata foi financiada por fundos nacionais através da FCT - Fundação para a Ciência e a Tecnologia, I.P., no âmbito do projeto UIDB/04011/2020 e do projeto UIDB/05583/2020. Agradecemos adicionalmente à Universidade de Trás-os-Montes e Alto Douro, ao Instituto Politécnico de 
Viseu, ao Centro de Estudos Transdisciplinares para o Desenvolvimento - CETRAD e ao Centro de Investigação em Serviços Digitais - CISeD, pelo apoio prestado.

\section{REFERÊNCIAS}

Administração Central do Sistema de Saúde (2019). Monitorização da Rede Nacional de Cuidados Continuados Integrados (RNCCI) 2019. Departamento de Gestão da Rede de Serviços e Recursos em Saúde (DRS). http://www.acss.min-saude.pt/wp-content/uploads/2020/08/Relatorio_Monitorizacao_RNCCI-2019.pdf

Administração Central do Sistema de Saúde (2017b). Monitorização da Rede Nacional de Cuidados Continuados Integrados (RNCCl) 2017. Departamento de Gestão da Rede de Serviços e Recursos em Saúde (DRS). http://www.acss.min-saude.pt/wp-content/uploads/2018/11/Relatorio-deMonitorizacao-da-RNCCl-2017.pdf

Administração Central do Sistema de Saúde (2017a). Monitorização da Rede Nacional de Cuidados Continuados Integrados (RNCCI) 2016. Departamento de Gestão da Rede de Serviços e Recursos em Saúde (DRS). http://www.acss.min-saude.pt/wp-content/uploads/2016/07/RNCCl-RelatorioMonitorizacao-Anual-2016.pdf

Administração Central do Sistema de Saúde (2015a). Monitorização da Rede Nacional de Cuidados Continuados Integrados (RNCCI) 2014. Departamento de Gestão da Rede de Serviços e Recursos em Saúde (DRS), Núcleo Funcional da Rede Nacional de Cuidados Continuados Integrados. http://www.acss.min-saude.pt/wp-content/uploads/2016/07/Relatorio-de-Monitorizacao-Anualda-RNCCl-2014.pdf

Administração Central do Sistema de Saúde (2015b). Relatório e Contas de 2014. Ministério da Saúde.

http://www.acss.minsaude.pt//instrumentos_de_gestao_reg/Relatório\%20e\%20Contas\%20da\%20Gerência\%202015_A CSS.pdf

Administração Central do Sistema de Saúde (2016). Relatório e Contas de 2015. Ministério da Saúde. http://www.acss.min-saude.pt//wp-content/uploads/2016/10/Relatorio-e-Contas-da-Gerencia2016_ACSS.pdf

Benbassat, J. \& Taragin, M. (2000). Hospital Readmissions as a Measure of Quality of Health Care: Advantages and Limitations. Archives of Internal Medicine, 160(8), 1074-1081. https://doi.org/ $\underline{10.1001 / a r c h i n t e .160 .8 .1074}$

Cabral, N.C., Amador, O.M., \& Martins, G.W. (2010). A reforma do setor da saúde: uma realidade iminente? Almedina.

Campos, A.C. (2001). O envelhecimento da população e os gastos com a saúde. Revista Portuguesa de Saúde Pública, 19(1), 25-27. https://run.unl.pt/bitstream/10362/16414/1/RUN\%20\%20RPSP\%20-\%20v19n1a03\%20-\%20p.25-27.pdf

Campos, A.C. (2008). Reformas na Saúde: o fio condutor. Almedina.

Carvalho, A.B., Sobral, M.J., \& Rainho, M.J. (2016). A National Referral of an Integrated Network of Continuing Care: A Case Study. Atención Primaria, Número Especial: World Congress of Health Research, 48(Supl C Septiembre), 81. https://www.elsevier.es/es-revista-atencion-primaria-27pdf-X0212656716593638

Herrera, A.C., Wittenberg, R.D., Costa-Font, J., Gori, C., di Maio, A., Patxot, C., Pickard, L., Pozzi, A., \& Rothgang, H. (2006). Future long-term care expenditure in Germany, Spain, Italy and the United Kingdom. Ageing and Society, 26(2), 285-302. https://doi.org/10.1017/S0144686X05004289 
Decreto-Lei n. 101/2006, de 6 de junho de 2006 (2006). Dispõe sobre a criação da Rede Nacional de Cuidados Continuados Integrados. Portugal: Diário da República, 109(1A), 3856-3865. https://dre.pt/pesquisa/-/search/353934/details/maximized

Decreto-Lei n.o 281/2003 de 8 de novembro de 2002 (2003). Dispõe sobre a criação de uma rede de cuidados continuados de saúde. Portugal: Diário da República, 259(1A), 7492-7499. https://dre.pt/pesquisa/-/search/468981/details/maximized

Decreto-Lei n.o 56/2006, de 15 de março de 2006 (2006). Dispõe sobre a distribuição dos resultados líquidos dos jogos sociais explorados pela Santa Casa da Misericórdia de Lisboa. Portugal: Diário da República, 53(1A), 1913-1915. https://dre.pt/pesquisa/-/search/667323/details/maximized

Despacho Conjunto n.o 407/98, de 18 de junho de 1998 (1998). Dispões sobre orientações reguladoras da intervenção articulada do apoio social e dos cuidados de saúde continuados dirigidos às pessoas em situação de dependência. Portugal. Diário da República, 138(2), 8328-8332. http://www.seg-social.pt/documents/10152/35243/Desp_C_407_98

Despacho n.o 16234/2005, 26 de julho de 2005 (2005). Dispões sobre os trabalhos da Comissão para o Desenvolvimento dos Cuidados de Saúde às Pessoas Idosas e às Pessoas em Situação de Dependência. Portugal. Diário da República, 142(2), 10787-10788. https://dre.tretas.org/pdfs/2005/07/26/dre-188134.pdf

Dias, A.S.S. (2012). Referenciação para unidades de internamento de cuidados paliativos portugueses: Quando? quem? e porquê? [Dissertação de mestrado não publicada]. Universidade Católica Portuguesa. https://repositorio.ucp.pt/handle/10400.14/10518

Entidade Reguladora da Saúde (2015). Acesso, Qualidade e Concorrência nos Cuidados Continuados e Paliativos. Porto. https://www.ers.pt/uploads/writer_file/document/1647/ERS_EEstudo_Cuidados_Continuados___vers_o_final.pdf

Entidade Reguladora da Saúde (2013). Avaliação do Acesso dos Utentes aos Cuidados Continuados de Saúde. Porto. https://www.ers.pt/uploads/writer_file/document/824/Cuidados_continuados.pdf Escoval, A., Fernandes, A., Matos, T., \& Santos, A. (2010). Plano Nacional De Saúde 2011-2016: Cuidados de saúde hospitalares. Escola Nacional de Saúde Pública. http://1nj5ms2lli5hdggbe3mm7ms5.wpengine.netdna-cdn.com/fils/2010/08/CSH2.pdf

Fernandes, A.F.F. (2013). Dificuldades sentidas pelas equipas dos Cuidados de Saúde Primários, na referenciação de utentes para a $R N C C /$ [Dissertação de mestrado não publicada]. Instituto Politécnico de Bragança. https://bibliotecadigital.ipb.pt/handle/10198/9931

Ferreira, L.G.O. (2012). O efeito da referenciação de utentes para a rede nacional de cuidados continuados integrados sobre a demora média dos internamentos no Centro Hospitalar do Porto [Dissertação de mestrado não publicada]. Faculdade de Economia da Universidade do Porto. http://repositorio.chporto.pt/bitstream/10400.16/1363/1/Ferreira-L.pdf

Gibson, M. J. (2006). Internacional Perspectives on Long-Term Care. AARP Public Policy Institute. https://assets.aarp.org/www.aarp.org_/cs/gap/ldrstudy_longterm_030507.pdf

Gonçalves, A.I.R. (2013). Estudo da adequação da rede nacional de cuidados continuados integrados às necessidades da população - o conhecimento da realidade como instrumento de apoio à gestão [Dissertação de mestrado não publicada]. Instituto Politécnico de Bragança. https://bibliotecadigital.ipb.pt/handle/10198/8185.

Goossen, W. (2000). Uso de registos electrónicos dos pacientes para colher conjuntos mínimos de dados baseados numa terminologia unificada de enfermagem. Enfermagem, 18, 5-22.

Halasyamani, L., Kripalani, S., Coleman, E., Schnipper, J., Van Walraven, C., Nagamine, J., Torcson, P., Bookwalter, T., Budnitz, T., \& Manning, D. (2006). Transition of Care for Hospitalized Elderly Patients - Development of a Discharge Checklist for Hospitalists. Journal of Hospital Medicine, 1(6), 354-360. http://doi.org/10.1002/jhm.129 
Instituto da Segurança Social (2019). Guia Prático - Rede Nacional de Cuidados Continuados Integrados (N37 - $\quad$ v4.24). http://www.segsocial.pt/documents/10152/27195/N37_rede_nacional_cuidados_continuados_integrados_rncci/f 2a042b4-d64f-44e8-8b68-b691c7b5010a

Jha, A., Orav, E., \& Epstein, A. (2009). Public Reporting of Discharge Planning and Rates of Readmissions. The New England Journal of Medicine, 361(127), 2637-2645. http://doi.org/10.1056/NEJMsa0904859

Ministério da Saúde (2018). Nota explicativa do OE 2019. www.parlamento.pt/Documents/2020/janeiro/Nexplicativa-SAUDE.pdf

Monteiro, O.M.C. (2012). Eficiência dos cuidados continuados integrados: Hospitais do serviço nacional de saúde ou rede nacional de cuidados integrados [Dissertação de mestrado não publicada]. Universidade de Lisboa, Instituto Superior de Ciências Sociais e Políticas. https://www.repository.utl.pt/handle/10400.5/5870.

Observatório Português dos Sistemas de Saúde (2006). Relatório de primavera 2006 - Um Ano de Governação em Saúde: Sentidos e Significados. Coimbra: Centro de Estudos e Investigação em Saúde da Universidade de Coimbra. http://opss.pt/wpcontent/uploads/2018/06/RelatorioPrimavera2006_OPSS.pdf

Parker, S.G. (2005). Do current discharge arrangements from inpatient hospital care for the elderly reduce readmission rates, the length of inpatient stay or mortality, or improve health status?. Copenhagen: World Health Organization, Regional Office for Europe. http://www.euro.who.int/Document/E87542.pdf

Pestana, H. (2007). Tecnologias de Informação e Comunicação em Saúde: uma possibilidade ou o futuro?. Nursing, 219, 12-16.

Petronilho, F.A.S. (2010). A transição dos membros da família para o exercício do papel de cuidadores quando incorporam um membro dependente no auto-cuidado: uma revisão de literatura. Revista de Investigação em Enfermagem, fev., 43-58. http://repositorium.sdum.uminho.pt/bitstream/1822/21668/2/A\%20transição\%20dos\%20membros \%20da\%20família\%20para\%200\%20exercício\%20do\%20papel\%20de\%20cuidadores $\% 20 q u a n d o \%$ 20incorporam $\% 20$ um $\% 20$ membro\%20dependente $\% 20$ no $\% 20$ autocuidado $\% 20$ \%20uma\%20revisão\%20da\%20literatura.pdf

Portaria no 17/2019 de 15 de janeiro de 2019. Ministério das Finanças, Trabalho, Solidariedade e Segurança Social e Saúde. Define os preços dos cuidados de saúde e de apoio social prestados nas unidades de internamento e de ambulatório da Rede Nacional de Cuidados Continuados Integrados. Portugal: Diário da República, 10(1), 196-198. https://dre.pt/pesquisa//search/117821815/details/maximized

Portaria no 254/2018 de 07 de setembro de 2018. Ministério da saúde. Altera a Portaria n.o 207/2017, de 11 de julho, que aprova os Regulamentos e as Tabelas de Preços das Instituições e Serviços Integrados no Serviço Nacional de Saúde (SNS), procede à regulamentação do Sistema Integrado de Gestão de Inscritos para Cirurgia (SIGIC), que passa a integrar o Sistema Integrado de Gestão do Acesso ao SNS (SIGA SNS), e define os preços e as condições em que se pode efetuar a remuneração da produção adicional realizada pelas equipas. Portugal: Diário da República, 173(1), 4497-4706. https://dre.pt/home/-/dre/116353279/details/maximized

Portaria no 234/2015 de 07 de agosto de 2015. Ministério da saúde. Aprova o Regulamento e as Tabelas de Preços das Instituições e Serviços Integrados no Serviço Nacional de Saúde e revoga a Portaria n.o 20/2014, de 29 de janeiro. Portugal: Diário da República, 153(1), 5516-5654. https://dre.pt/home/-/dre/69968713/details/maximized

Portaria no 174/2014 de 10 de setembro de 2014. Ministérios das Finanças, da Saúde e da Solidariedade, Emprego e Segurança Social. Define as condições de instalação e funcionamento a 
que devem obedecer as unidades de internamento e de ambulatório e as condições de funcionamento das equipas de gestão de altas e as equipas de cuidados continuados integrados da Rede Nacional de Cuidados Continuados Integrados. Portugal: Diário da República, 174(1B), 48654882. https://dre.pt/pesquisa/-/search/56720777/details/maximized

Portaria no 360/2013 de 16 de dezembro de 2013. Ministérios das Finanças, da Saúde e da Solidariedade, Emprego e Segurança Social. Fixa os preços dos cuidados de saúde e de apoio social prestados nas unidades de internamento e de ambulatório da $\mathrm{RNCCl}$ a praticar no ano de 2013. Portugal: Diário da República, 243(1B), 6780. https://dre.pt/pesquisa//search/483937/details/maximized

Rainho, M.J., Carvalho, A.B., \& Sobral, M.J. (2020). Gestão da alta hospitalar e referenciação para Rede Nacional de Cuidados Continuados Integrados: um estudo de caso. Egitania Sciencia, 2(27), 143-161. http://egitaniasciencia2.ipg.pt/index.php/egitania_sciencia/issue/view/27

Rego, G. \& Nunes, R. (Coord.) (2010). Gestão da Saúde. Prata \& Rodrigues Publicações.

Resolução de Conselho de Ministros n.o 84/2005, de 27 de Abril de 2005. Dispõe sobre a criação Comissão para o Desenvolvimento dos Cuidados de Saúde às Pessoas Idosas e às Pessoas em Situação de Dependência. Portugal: Diário da República, 81(1B), 3200- 3201. https://dre.pt/pesquisa/-/search/533215/details/maximized

Resolução do Conselho de Ministros n.o 59/2002, de 22 de Março de 2002. Dispõe sobre o objectivo dos cuidados continuados integrados assentes em novas configurações organizativas. Portugal: Diário da República, 69(1B), 2752-2754. https://dre.pt/pesquisa//search/262643/details/maximized

Simões, J. (2010). 30 Anos do Serviço Nacional de Saúde: um percurso comentado. Almedina.

Sousa, P. (2009). O sistema de saúde em Portugal: realizações e desafios. Acta Paul. Enf., 22(Spc), 884-894. https://www.scielo.br/pdf/ape/v22nspe/09.pdf

Sousa, P.A.F. (2006). Sistemas de partilha de informação de enfermagem entre contextos de cuidados de saúde: um modelo explicativo. Formasau.

Unidade de Missão para os Cuidados Continuados Integrados (2009a). Modelo de Referenciação de utentes. $\quad \mathrm{UMCCl}$ http://www.arsnorte.min-saude.pt/wpcontent/uploads/sites/3/2018/05/Directiva_Tecnica_3_UMCCI_2009_Modelo_Referenciacao_Do en.pdf

Unidade de Missão para os Cuidados Continuados Integrados (2009b). Guia da Rede Nacional de Cuidados Continuados Integrados (RNCCI). UMCCI. http://portaisars. azurewebsites.net/cuidadoscontinuados-integrados/rede-nacional-de-cuidados-continuados-integrados/

Unidade de Missão para os Cuidados Continuados Integrados (2011). Manual do Prestador recomendações para melhoria contínua. (1a ed). UMCCl. http://www.acss.min-saude.pt/wpcontent/uploads/2016/10/Man_Prestador_UMCCI-RNCCI.pdf 